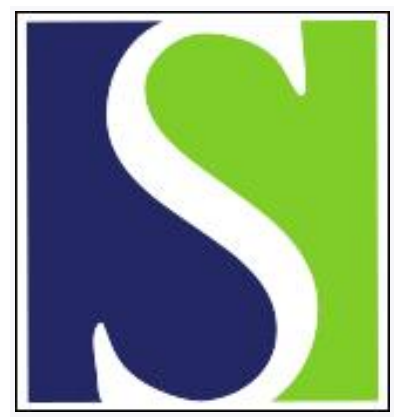

Scand J Work Environ Health 2016;42(4):261-272

https://doi.org/10.5271/sjweh.3576

Published online: 07 Jun 2016, Issue date: 01 Jul 2016

Effectiveness of very early workplace interventions to reduce sickness absence: a systematic review of the literature and meta-analysis

by Vargas-Prada S, Demou E, Lalloo D, Avila-Palencia I, Sanati KA, Sampere M, Freer K, Serra C, Macdonald EB

This systematic review identified a lack of evidence to support the effectiveness of "very early" (less than 15 days after the start of sickness absence) workplace intervention to reduce sick leave compared to usual care. Lack of consensus on definition of "very early/early" interventions, methodological design of studies, the extent, and timing of usual care provided and variable compliance between groups might explain the absence of demonstrated benefit.

Affiliation: Center for Research in Occupational Health, Universitat Pompeu Fabra. Carrer Doctor Aiguader 88, 08003-Barcelona, Spain. consol.serra@upf.edu

Refers to the following texts of the Journal: 2015;41(2):204-215 2013;39(1):37-45

The following article refers to this text: 2019;45(5):444-449

Key terms: early workplace intervention; intervention; meta-analysis; MSD; musculoskeletal disorder; return to work; review; RTW; sick leave; sickness absence; sickness absence; systematic review; workplace; workplace intervention

This article in PubMed: www.ncbi.nlm.nih.gov/pubmed/27271024

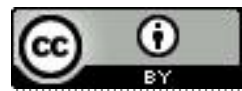




\title{
Effectiveness of very early workplace interventions to reduce sickness absence: a systematic review of the literature and meta-analysis
}

By Sergio Vargas-Prada, MD, PhD, 1, 2, 3, 4 Evangelia Demou, PhD, ,5, 6 Drushca Lalloo, MD, ${ }^{5}$ Ione AvilaPalencia, MPH, ${ }^{3,7,8}$ Kaveh A Sanati, MD, ${ }^{5,9}$ Maite Sampere, MD, PhD, ${ }^{10}$ Kerry Freer, MD, ${ }^{11}$ Consol Serra, $M D, P h D, 1,3,4,12$ Ewan B Macdonald, MD, OBE ${ }^{5}$

\begin{abstract}
Vargas-Prada S, Demou E, Lalloo D, Avila-Palencia I, Sanati KA, Sampere M, Freer K, Serra C, Macdonald EB. Effectiveness of very early workplace interventions to reduce sickness absence: a systematic review of the literature and meta-analysis. Scand J Work Environ Health. 2016;42(4):261-272. doi:10.5271/sjweh.3576
\end{abstract}

Objective The aim of this review was to investigate the effectiveness of workplace return-to-work (RTW) interventions delivered at very early stages ( $<15$ days) of sickness absence (SA).

Methods A systematic literature search was conducted in PubMed, Health Management Information Consortium (HMIC), Cochrane library database, Cumulative Index to Nursing and Allied Health Literature (CINAHL), PsychInfo and Embase. Using pre-established criteria, independent pairs of researchers carried out the study selection, quality appraisal and data extraction. Workplace interventions before day 15 of SA, were included. Primary outcome measures included rates of and time until RTW, productivity loss, and recurrences of SA.

Results We found limited available evidence on the benefits of "very early" workplace interventions in terms of RTW after a SA episode compared to usual care. Only three randomized controlled trials classed as high or intermediate quality were identified. Early part-time sick leave together with appropriate job modifications led to a reduction in the duration and recurrence of SA. There is evidence of benefit of intervening during the first two weeks of SA for musculoskeletal disorders.

Conclusion Our review has identified a lack of evidence from the literature at this time point to support "very early" intervention compared to usual care. The methodological design of the studies, notably the extent and timing of usual care provided and variable compliance/crossover between groups could however explain the lack of demonstrated benefit. Consensus is required on the definition of "early" and "very early" interventions, and further research is recommended to improve understanding of the factors influencing when and how best to intervene for maximum gain.

Key terms musculoskeletal disorder; MSD; return to work; RTW; sick leave.

1 Center for Research in Occupational Health (CiSAL), Universitat Pompeu Fabra, Barcelona, Spain.

2 Unidad Central de Contingencias Comunes (U3C), ASEPEYO, Barcelona, Spain.

3 CIBER of Epidemiology and Public Health, Spain.

4 IMIM (Hospital del Mar Research Institute), Barcelona, Spain.

5 Healthy Working Lives Group, Institute of Health and Wellbeing, College of Medical, Veterinary and Life Sciences, University of Glasgow, Glasgow, UK.

$6 \mathrm{MRC/CSO}$ Social and Public Health Sciences Unit, Institute of Health and Wellbeing, College of Medical, Veterinary and Life Sciences, University of Glasgow, Glasgow, UK.

7 ISGlobal, Centre for Research in Environmental Epidemiology (CREAL), Barcelona, Spain.

8 Department of Experimental and Health Sciences, Universitat Pompeu Fabra (UPF), Barcelona, Spain.

9 Epsom and St Helier University Hospitals NHS Trust, Carshalton, Surrey, SM5 1AA, UK.

10 Mutual Midat Cyclops (MC Mutual), Barcelona, Spain.

11 Health Management Limited, Glasgow, UK.

12 Occupational Health Service, Parc de Salut MAR, Barcelona, Spain.

Address correspondence to Consol Serra, MD, PhD. Center for Research in Occupational Health - Universitat Pompeu Fabra. Carrer Doctor Aiguader 88, 08003-Barcelona, Spain. [E-mail: consol.serra@upf.edu]. 
Sickness absence (SA) remains a significant problem globally, notably in developed countries (1). For example, in the UK (2014-2015), 23.3 million days were lost due to work-related ill health, 4.1 million due to workplace injuries (2), and it has been estimated that two million people are suffering from an illness (long standing as well as new cases) they believe is caused or made worse by their current or past work (2). Musculoskeletal disorders (MSD) and mental health problems such as depression and anxiety accounted for the majority of days lost due to work-related ill health (2). In a cross-national comparative study (3), musculoskeletal and mental health disorders accounted for almost half of the registered SA episodes that lasted $>2$ weeks and occurred between January and December 2010 in the Netherlands and Sweden.

In addition to substantial cost implications for employers and social security systems, SA has a huge impact on well-being, self-esteem and the livelihood of workers (4). Recent pension policy changes and workforce demographics, with a shift towards extending working lives and management of the ageing worker (5), are also likely to have important implications on attendance management. In order to address this, management programs to reduce SA have become an inherent element of workplace and organizational policies.

Several workplace evidence-based return-to-work (RTW) interventions for workers on sick leave have been identified in the literature (6-10). These interventions include maintaining contact with an occupational physician (OP) or nurse $(11,12)$, case management (13-15), work modification $(13,15)$ and health promotion activities (16). However, the majority of interventions are focused on long-term SA.

It has been observed that the probability of resuming work diminishes with time on sick leave (17). Therefore, early intervention to enhance RTW has been identified as a key priority in the management of SA and disability (1). Few "very early" (defined here as starting $<15$ days after the start of SA) intervention studies $(13,18$, $19)$, and early workplace interventions for sick-listed employees (20-22) exist to our knowledge, despite the fact that there are a number of commercially successful companies offering SA management services to employers that involve the employee being seen or telephoned on the first day of absence $(23,24)$. Some of those interventions implemented in the very early/ early stages of SA episodes indicate that they may result in a quicker RTW and be cost-effective $(20,22)$. For example, the implementation of simple and inexpensive workplace enhancements, such as task modifications or job accommodation, are likely to be cost-beneficial in terms of returning to work (17). Timing of enrolment of workers into the intervention, together with the RTW pattern in the target population and the nature of the intervention, are crucial factors in order to achieve a successful RTW (17). However, current evidence remains inconclusive about the optimal timing of implementing workplace interventions. This has led to a lack of consistency in the definition of what a "very early" versus "early" intervention means. Based on these findings, this systematic review aims to (i) fill the knowledge gap on the effectiveness of workplace interventions for RTW delivered at very early stages (before day 15) of SA, (ii) understand the health and organizational factors influencing the effectiveness of very early SA workplace interventions, and (iii) enable a complete mapping of the current evidence to inform employees, employers, and health professionals dealing with SA management.

\section{Methods}

This systematic review sought to answer whether very early interventions at the workplace are effective to reduce SA. To this end, we have considered all workplace interventions, defined as all interventions carried out in the workplace before day 15 of SA, implemented directly or indirectly by the employer, including the involvement and participation of a variety of professionals from internal (company/sector occupational health departments) or external occupational health services. Interventions involving economic or financial RTW incentives or dismissal and disciplinary interventions to promote RTW are not under the scope of this review and thus they were not taken into account.

\section{Search strategy}

An electronic search was carried out using the following databases: MEDLINE (PubMed), Health Management Information Consortium (HMIC), Cochrane library database, Cumulative Index to Nursing and Allied Health Literature (CINAHL), PsychInfo and Embase. Our search strategy was applied similarly to all databases and combined four blocks of keywords or MEsH terms intended to cover all different aspects of our review: (i) setting: "workplace", "employer", "manager", "management" and "nurse administrator"; (ii) early intervention: "early intervention", "early stage", "call handling", "signposting", "occupational health" and "case management"; (iii) outcome: "return-to-work", "employment", "unemployment", "sick leave", "work absence", "sickness absence", and "absenteeism"; (iv) type of study: "randomized controlled trials", "clinical trial", "random allocation", "blind method" and "placebo".

The search strategy used was: (((((workplace[mesh:noexp]) OR (work*[tiab]) OR (manager[tiab] OR management[tiab]) OR (Nurse 
Administrators[mesh]) OR (employer[tiab]) OR (Employment[mesh]) OR (employment[tiab])) AND (()arly[tiab] OR start[tiab] OR begin*[tiab] OR initial[tiab]) AND interven*[tiab]) OR (“call handling”[tiab] OR call handling[tiab]) OR (telephone[mesh:noexp]) OR (call centre[tiab]) OR ((telephone[tiab] AND interven*[tiab]) OR advise[tiab] OR advice[tiab] OR support[tiab]) OR (web based intervention[tiab] OR online intervention[tiab]) OR (internet[mesh:noexp]) OR (health advice[tiab] OR infection advice[tiab]) OR (Influenza, Human[mesh]) OR (occupational health[tiab]) OR (occupational health[mesh:noexp]) OR (physiotherapy[tiab] OR physical therapy[tiab]) OR (Physical Therapy Modalities[mesh]) OR (Occupational Medicine[mesh]) OR (occupational medicine[tiab]) OR (Occupational Health Services[mesh]) OR (occupational[tiab] AND (physician[tiab] OR nurs*[tiab] OR safety[tiab])) OR (industrial hygiene[tiab]) OR (Counseling[mesh]) OR (counsel*[tiab]) OR (Human Engineering[mesh]) OR (ergonomics[tiab]) OR (Psychology, Industrial[mesh]) OR (redeployment[tiab]) OR ((work[tiab] OR job[tiab]) AND (adapt*[tiab] OR adjust*[tiab] OR restrict*[tiab])) OR (Healthy People Programs[mesh]) OR (case management[tiab] OR managed care[tiab] OR case manager[tiab]) OR (day[tiab] AND ("15"[tiab] OR fifteen[tiab]))) AND (((return*[tiab] AND work[tiab]) OR (unemploy*[tiab]) OR (Unemployment[mesh]) OR (Retirement[mesh]) OR (retire*[tiab]) OR ((sick*[tiab] OR work[tiab]) AND (leave[tiab] OR absen*[tiab])) OR (absenteeism[tiab]) OR (sick leave[mesh:noexp] OR absenteeism) OR ("short term"'[tiab] AND (absen*[tiab] OR sick*[tiab])) OR (work[tiab] AND (abilit*[tiab] OR capacit*[tiab] OR capabil*[tiab])) OR (work[tiab] AND (disabilit*[tiab] OR rehabilitation[tiab] OR retention[tiab] OR loss[tiab])) OR (Occupational Diseases[mesh]) OR (workability[tiab]) OR (employab*[tiab]) OR (employee*[tiab]))) AND ((((Randomized Controlled Trials as Topic[mesh:noexp]) OR (randomized controlled trial[mesh:noexp]) OR (Random Allocation[mesh:noexp]) OR (Double Blind Method[mesh:noexp]) OR (Single Blind Method[mesh:noexp]) OR (clinical trial[mesh:noexp]) OR (clinical trial, phase i[pt]) OR (clinical trial, phase ii[pt]) OR (clinical trial, phase iii[pt]) OR (clinical trial, phase iv[pt]) OR (controlled clinical trial[pt]) OR (randomized controlled trial[pt]) OR (multicenter study[pt]) OR (clinical trial[pt]) OR (Clinical Trials as topic[mesh])) OR ((clinical[tiab] AND trial*[tiab]) OR ((singl*[tiab] OR doubl*[tiab] OR treb*[tiab] OR tripl*[tiab]) AND (blind*[tiab] OR mask*[tiab])) OR (placebos[mesh:noexp]) OR (placebo*[tiab]) OR (randomly allocated[tiab]) OR (allocated[tiab] AND random*[tiab]) OR ((cluster[tiab] AND trial*[tiab]) OR cluster random* AND trial*[tiab]))) NOT ((case report[tiab]) OR (letter[mesh:noexp]) OR (historical article[mesh:noexp])))) AND (english[la])).
Likewise, the reference lists of those papers which fulfilled our inclusion criteria were carefully screened to identify additional studies that were not included in our electronic search.

\section{Study selection and eligibility criteria}

Randomized controlled trials, controlled trials, clusterrandomized trials, cross-over designs, before and after studies and interrupted time-series published in English until September 2014 were included if they assessed the effectiveness of workplace interventions to reduce SA in workers who were on sick leave $\leq 15$ days. Outcome measures after the implementation of the intervention included in this review were: (i) Primary: (a) rates and time until return-to-work, (b) productivity loss and days lost, (c) duration of sick leave, and (d) recurrences of SA episodes; and (ii) Secondary: (a) satisfaction with the intervention, either of employees, line managers or employers, (b) functional disability, (c) pain intensity and interference with work or sleep, (d) self-rated health, (e) depression or mental health disorders, and (f) healthcare utilization.

After excluding duplicates, a total of 4124 citations were obtained from the electronic search. All citations were gathered in four homogeneous groups (similar number of citations included) based on alphabetical order according to the first letter of the first author. Two reviewers per group independently screened titles and, when necessary, abstracts for eligibility. Of these, 131 potentially suitable publications were identified from the electronic search and 2 further studies were identified from the references lists, yielding a total of 133 studies for all which the fulltext was obtained. Those 133 studies were grouped again in the same four groups and reviewed by independent pairs of reviewers. Disagreements within pairs $(10.5 \%$ of the 133 identified publications) were resolved by discussion and, where necessary, by a third reviewer who made the final decision. All authors participated as reviewers for screening the citations and full papers using established inclusion criteria defined in the previous paragraphs. Five papers reporting findings from 4 different studies (two papers came from the same study) met our inclusion criteria and were considered for quality assessment.

\section{Quality and bias assessment}

Three reviewers independently assessed the methodological quality of each of the five selected papers (19, 25-28) using the Consolidated Standards of Reporting Trials (CONSORT) Statement (29) for randomized studies and the Transparent Reporting of Evaluations with Non-randomized Designs (TREND) Statement (30) for non-randomized studies. 
The CONSORT scale (29) included 25 items (some of them with sub-items) grouped into six areas: title and abstract; introduction; methods; results; discussion; and other information. Similarly, the TREND scale (29) has 22 items (also, some of them with sub-items) organized into five areas: title and abstract; introduction; methods; results; and discussion.

Regarding the scale that was used, each sub-item was rated as 1 when the requirement was met, 0.5 when the requirement was partially met, or 0 when the requirement was unclearly or not met. For each study, a final score was obtained by summing all responses from those sub-items that were applicable to the study. Studies were rated as high quality when the final score was $>80 \%$ of the maximum possible score, intermediate quality when the score was $60-79 \%$, and low quality when it was $<60 \%$ (31). Disagreements among the three reviewers were resolved by consensus. After the quality assessment, one paper was rated as low-quality (28) and, on this basis - and given it was a considerably different design that did not provide comparable data - it was excluded. Major reasons for low quality were the absence of a comparison group, absence of a description of flow of participants through each stage of study, no report of effect sizes estimations and confidence intervals $(\mathrm{CI})$ for primary and secondary outcomes, and no discussion about workplace barriers in the implementation process of the intervention. Finally, three studies (four papers) of high or intermediate methodological quality were included in our systematic review (figure 1 and table 1).

The Cochrane Collaboration tool (32) was used to assess the risk of bias in those three randomized controlled trials (four papers) $(19,25-27)$. Selection bias (adequate sequence generation, allocation concealment), attrition bias (incomplete outcome data) and reporting bias (selective outcome reporting) were assessed. Items on performance and detection bias (blinding of participants, personnel and outcome assessment) were not evaluated because none of the included interventions could blind participants or care providers.

\section{Data extraction and synthesis}

Selected information was obtained from each of the three studies $(19,25-27)$, including publication year, country of origin, study epidemiological design, setting, study participants, sample size, response rate. Likewise, characteristics and type of intervention, day of intervention and primary and secondary outcome measurements were also documented from each paper. Furthermore, main results related to the considered outcomes (including risk estimates and their corresponding $95 \% \mathrm{CI}$ when available) and the inclusion of potential confounders in the analyses were also collected (table 2).

\section{Meta-analysis}

Meta-analysis was carried out using the 5.3 version of Review Manager (RevMan) software (The Nordic Cochrane Centre, The Cochrane Collaboration. Copenhagen, Denmark) to estimate the combined effect of the primary outcome (RTW) from all the 3 early interventions included $(19,25-27)$. Random effects models were chosen to assign weights in the analysis, and forest plots were depicted. A pooled effect size [odds ratio (OR)] and its corresponding 95\% CI were calculated, and

Table 1. Methodological quality appraisal of the included studies with intermediate or high quality scores (CONSORT Statement checklist). Quality score: $10 \mathrm{~W}=<60 \%$, moderate $=60-79.9 \%$, high $=\geq 80 \%$ of maximum score. [NA=not applicable.]

\begin{tabular}{|c|c|c|c|c|}
\hline & & $\begin{array}{l}\text { Rebergen } \\
\text { et al } \\
(2009)^{a}\end{array}$ & $\begin{array}{l}\text { Verbeek } \\
\text { et al } \\
(2002)^{b}\end{array}$ & $\begin{array}{l}\text { Viikari- } \\
\text { Juntura et al } \\
\text { (2012) / Shiri } \\
\text { et al (2013) }\end{array}$ \\
\hline $1 \mathrm{a}$ & Title & 1 & 1 & 1 \\
\hline $1 b$ & Abstract & 1 & 1 & 1 \\
\hline $2 \mathrm{a}$ & Background & 1 & 1 & 1 \\
\hline $2 b$ & Objectives & 1 & 1 & 1 \\
\hline $3 a$ & Trial design & 0.5 & 1 & 1 \\
\hline $3 b$ & Changes to trial design & NA & NA & NA \\
\hline $4 a$ & Participants & 1 & 1 & 1 \\
\hline $4 b$ & Study settings & 1 & 1 & 1 \\
\hline 5 & Interventions & 1 & 1 & 1 \\
\hline $6 a$ & Outcomes & 1 & 1 & 1 \\
\hline $6 b$ & Changes to outcomes & NA & NA & NA \\
\hline $7 a$ & Sample size & 1 & 1 & 1 \\
\hline $7 b$ & $\begin{array}{l}\text { Interim analyses and stopping } \\
\text { guidelines } \\
\text { Randomization }\end{array}$ & $N A$ & NA & $\mathrm{NA}$ \\
\hline $8 a$ & Sequence generation & 1 & 1 & 1 \\
\hline $8 b$ & Type & 1 & 1 & 1 \\
\hline 9 & $\begin{array}{l}\text { Allocation concealment } \\
\text { mechanism }\end{array}$ & 1 & 1 & 1 \\
\hline 10 & Implementation & 1 & 1 & 1 \\
\hline $11 a$ & Blinding & 1 & 1 & 0 \\
\hline $11 b$ & Similarity of interventions & NA & NA & NA \\
\hline $12 \mathrm{a}$ & Statistical methods & 1 & 1 & 1 \\
\hline $12 b$ & Additional analyses & 1 & 1 & 1 \\
\hline $13 a$ & Participant flow & 1 & 0.5 & 1 \\
\hline $13 b$ & Losses and exclusions & 1 & 0.5 & 1 \\
\hline $14 a$ & $\begin{array}{l}\text { Dates defining the periods of } \\
\text { recruitment and follow-up }\end{array}$ & 1 & 0.5 & 1 \\
\hline $14 b$ & Reason for stopped trial & NA & NA & 1 \\
\hline 15 & Baseline data & 1 & 1 & 1 \\
\hline 16 & Numbers analysed & 1 & 1 & 1 \\
\hline $17 a$ & Outcomes and estimation & 1 & 1 & 1 \\
\hline $17 b$ & Binary outcomes & 1 & 0 & 0.5 \\
\hline 18 & Ancillary analyses & 1 & 1 & 1 \\
\hline 19 & Harms & 0 & 0 & 0.5 \\
\hline 20 & Limitations & 1 & 1 & 1 \\
\hline 21 & $\begin{array}{l}\text { Generalizability (external } \\
\text { validity) }\end{array}$ & 1 & 1 & 1 \\
\hline 22 & Interpretation & 1 & 1 & 1 \\
\hline 23 & Registration & 1 & 0 & 1 \\
\hline 24 & Protocol & 1 & 0 & 1 \\
\hline 25 & Funding & 1 & 0 & 1 \\
\hline
\end{tabular}

a Total score 30.5 , quality rate $95.3 \%$

b Total score 25.5 , quality rate $79.7 \%$.

' Total score 30 , quality rate $93.8 \%$. 


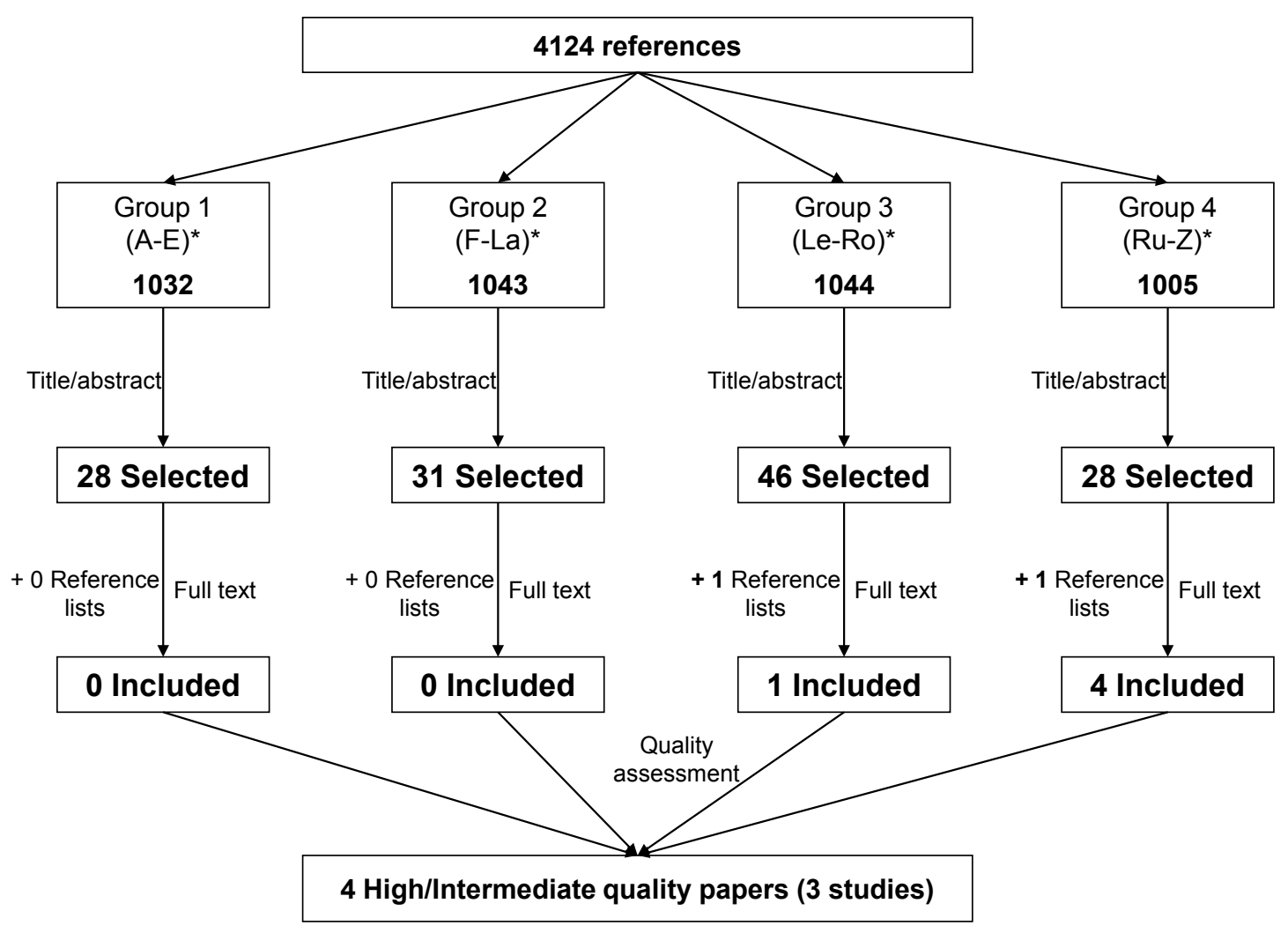

Figure 1. Flow chart for selection and assessment of included studies. ${ }^{*}$ References grouped in alphabetical order according to the first letter of the first author.

the I2 index was used to quantify the total variability between studies due to heterogeneity. $\mathrm{I}^{2}$ values $>50 \%$ were considered as "high heterogeneity" (33).

\section{Results}

\section{Quality assessment}

Of the three randomized controlled trials included in our review, two (25-27) were classified as "high quality" (obtained a score $>80 \%$ of the maximum possible score in the quality assessment).

\section{Characteristics of included studies}

The characteristics of the included studies are described in table 2. All the studies were conducted in Europe, two of them in the Netherlands $(19,25)$ and one in Finland $(26,27)$. Police workers on sick leave due to mental health problems (25), health care and university workers with low back pain (19) and workers with disabling MSD $(26,27)$ were included in the interventions assessed. The number of participants in the three randomized interventions ranged from $63(26,27)$ to 240 (25). The interventions were implemented in occupational health $(\mathrm{OH})$ services of police departments (25), academic and peripheral hospitals (19) and public and private enterprises $(26,27)$.

Both Dutch studies performed a guideline-based care intervention, delivered by occupational physicians, with the aim of facilitating RTW among workers on sick leave for $<2$ weeks (25) and before day 10 (19). The intervention group was compared to usual care, delivered by a psychologist for those policemen with mental health problems (25) and by general practitioners (GP) (medical treatment) and the worker's supervisor (sick leave management) for workers with low-back pain (19). In the two studies $(19,25)$, counselling, $\mathrm{OH}$ intervention and case management to support the recovery of workers on sick leave were offered to workers that were randomized to the intervention group. In both guideline-based care interventions, occupational physicians assessed physical and psychosocial factors related to disability that arise from mental health problems and non-specific low-back pain respectively, with the aim of enhancing patients' problem-solving capacity and removing RTW barriers. Overall, the proposed interventions were: (i) remaining 
Table 2. Characteristics of included studies. [PSQ=Patient Satisfaction Questionnaire (short version); $\mathrm{OHPQ=0}$ ccupational Health (OH) Professionals Questionnaire; VAS=visual analog scale; RDQ=Roland Disability Questionnaire; RTW=return to work; NPH=Nottingham Health Profile.]

\begin{tabular}{llll}
\hline Study ID & Rebergen et al. 2009 & Verbeek et al (2002) & Viikari-Juntura et al (2012) /Shiri et al (2013) \\
\hline Country & The Netherlands & The Netherlands & Finland \\
Study design & Randomized controlled trial & Randomized controlled trial & Randomized controlled trial \\
Setting & OH services in 2 police departments & 8 academic and peripheral hospitals & 6 OH units in private and public enterprises \\
Participants & Police workers on sick leave due to & Health care and university workers with low & Long-term and full-time workers (18-60 years) \\
characteristics & mental health problems (MHP). & back pain on sick leave for at least 10 days and & with disabling musculoskeletal disorders, with- \\
and sample size & Sample size (response rate): & no consultation with occupational physician & out sick leave due musculoskeletal disorders \\
(response rate) & Baseline: 240 (49.1\%); Follow-up & (OP) (past 3 months). & $>2$ weeks (past month) and >30 days (past 3 \\
& (after 1 year): 224 (93.3\%). & Sample size (response rate): Baseline: 117 & months) and no surgery plans. \\
& & $(97.5 \%) ;$ Follow-up (after 3 months): 110 & Sample size (response rate): Baseline: 62 \\
& & $(94 \%) ;$ Follow-up (after 1 year): 108 (92.3\%) & (98.4\%); Follow-up (after 1 year): 56 (90.3\%).
\end{tabular}

\begin{tabular}{|c|c|c|}
\hline $\begin{array}{l}\text { Previous } \\
\text { sickness } \\
\text { absence }\end{array}$ & No & No \\
\hline Intervention & $\begin{array}{l}\text { Guideline-based care intervention } \\
\text { (delivered by } \mathrm{OH} \text { physician) vs usual } \\
\text { care (delivered by psychologist) }\end{array}$ & $\begin{array}{l}\text { Guideline-based care intervention (delivered } \\
\text { by } \mathrm{OH} \text { physician) vs usual care (delivered by } \\
\text { general practitioners and worker's supervisor) }\end{array}$ \\
\hline \multicolumn{3}{|l|}{ Intervention type } \\
\hline Call handling & No & No \\
\hline Counselling & Yes & Yes \\
\hline Signposting & No & Yes \\
\hline $\mathrm{OH}$ & Yes & Yes \\
\hline Case manage. & Yes & Yes \\
\hline Intervention day & $\begin{array}{l}1^{\text {st }} \text { week sick leave: case manager visit } \\
2^{\text {nd }} \text { week sick leave: consultation OP. }\end{array}$ & $\begin{array}{l}\text { Day 11: patients were eligible if they were on } \\
\text { sick leave for } \geq 10 \text { days. }{ }^{\text {b }}\end{array}$ \\
\hline
\end{tabular}

\section{$\begin{array}{llll}\text { Primary } & \text { (1) Time (in days) until partial or full } & \text { (1) Time (in days) until RTW; (2) Rate of }\end{array}$ outcomes RTW; and (2) Total productivity loss: recurrence; (3) Days lost (all reasons and duration of full sick leave (in days) +1 low back pain).}

Secondary outcomes

Main results year follow-up recurrences (in days). Treatment satisfaction by the $\quad$ (1) Pain intensity; (2) Functional disability; employee, employer and OP. $\quad$ (3) General health perception; (4) Healthcare utilization.

Yes: excluded if sick leave due musculoskeletal disorders $>2$ weeks (past month) and $>30$ days (past 3 months).

Part-time (P/T) sick leave intervention (reduce daily working time by about a half) vs full-time $(\mathrm{F} / \mathrm{T})$ sick leave

No
No
No
Yes
No

No

No

No

Before starting sick leave (pain severe enough to justify sick leave but still allow working reduced hours without deterioration).

(1) Sustained return to work ( $\geq 2$ weeks and $\geq 4$ weeks); and (2) Duration of sick leave (in days), and (3) One year follow-up recurrences (time to first recurrence and number);

(4) Productivity loss.

(1) Pain intensity; (2) Pain interference with

work and sleep; (3) region specific disability (4) Self-rated health; (5) Perceived quality of life; (6) Depression; (7) Sleep disturbance.

Primary: (1) Time (median days) to sustained RTW for $\geq 4$ weeks was shorter in $\mathrm{P} / \mathrm{T}$ sick leave intervention group (IG) than $F / T$ : 12 vs 20 respectively, $P=0.10$. Time to sustained RTW $\geq 2$ weeks was similar in both groups (median 9 days). Fully adjusted HR of RTW=1.84, 95\% Cl 1.2-2.8; (2) Mean duration of sickness leave (days) during the 12-month follow-up 20\% lower in IG; (3) Time (days) to the first recurrent sick leave was similar in both groups (29 P/T vs $27 \mathrm{~F} / \mathrm{T})$, but number of recurrent sick leaves/personyear was $20 \%$ lower in IG (6.5 vs 8.6 ); (4) Total productivity loss did not differ between both groups.

Secondary: (1), (2) and (3) Pain intensity, pain interference with work and sleep and regionspecific disability did not differ between both groups; (4) IG reported better self-rated health (marginally significant; $P=0.06$, adjusted):

(5) IG reported better perceived quality of life (significant; $P=0.01$, adjusted); (6) and (7) Depression and sleep disturbance did not differ between both groups.

Yes: age, pain interference with sleep and work, previous sickness absence at baseline, time since beginning of symptoms, body mass index. periods (past year), OP, children, type characteristics, functional disability, genera of function, work-relatedness and health and working conditions perception, severity of MHP. coping style, and health locus of control.

$30(93.8 \%)$ - High quality

Quality score $^{b} \quad 30.5(95.3 \%)$ - High quality $25.5(79.7 \%)$ - Intermediate quality

for intervention participation).

a Previous sickness absence from a relevant preceding time period (as part of inclusion
${ }^{b}$ In $36 \%$ of all the cases, the OP did not see the patients before 4 weeks of sick leave.

${ }^{c}$ Rate and \%: Study quality is rated as low, moderate or high if it scored less than $60 \%$, between $60 \%$ and $79.9 \%$, and $80 \%$ or more of the maximum score, respectively. 
active (19), (ii) advice about exercise and education (19), (iii) regular contact with supervisors/employers $(19,25)$, (iv) work modifications and accommodations $(19,25)$, (v) referral to specialists, such as GP or physiotherapists (19), and (vi) gradual RTW (25).

The Finnish intervention $(26,27)$ was quite different from the Dutch interventions. This study examined the effects of an early part-time (P/T) sick leave RTW and SA intervention among patients with musculoskeletal pain severe enough to justify sick leave (intervention group). The intervention group was compared to workers with the same characteristics of musculoskeletal pain but who were allocated to a full-time (F/T) sick leave (control group). To be included in the study, workers should not have been on sick leave for $>2$ weeks prior to visiting the occupational physician. Daily working time was reduced by about a half in the intervention group where workers were randomized to $\mathrm{P} / \mathrm{T}$ sick leave. The occupational physician sent a fit note to the worker's supervisor indicating the tentative duration of partial sick leave, whether certain physical tasks should be avoided, and if additional work modifications were needed. If any worker in the intervention group was unable to perform $\mathrm{P} / \mathrm{T}$ work tasks or return to full work after the initial $\mathrm{P} / \mathrm{T}$ sick leave (up to two months), $\mathrm{F} / \mathrm{T}$ sick leave was prescribed after medical assessment. No differences, in terms of compensation wages and social security benefits, were considered between the $\mathrm{P} / \mathrm{T}$ and F/T sick leave groups.

In general, the three main outcomes assessed in all the interventions were (i) RTW, measured in days until partial (25) or full RTW $(19,25)$, and sustained RTW, measured as the number of days of continued work- without a recurrent episode of sick leave $\geq 2$ and $\geq 4$ weeks after the end of $\mathrm{P} /$ or $\mathrm{F} / \mathrm{T}$ sick leave (27); (ii) duration (days lost) $(19,27)$ and recurrence rate of sick leave $(19,27)$; and (iii) productivity lost, measured either as the duration of sick leave days until full RTW added with number of days of recurrences on sick leave in the 1-year follow-up (25) or self-reported using a scale (34) based on the quality and the amount of work that the participant was able to perform compared to normal workday (26).

The main secondary outcomes assessed were: (i) satisfaction of workers, employers and occupational physicians (25); (ii) pain intensity, pain interference with work and sleep and disability $(19,26)$; (iii) self-rated health $(19,26)$ and perceived quality of life; (iv) depressive symptoms (26); (v) healthcare utilization (19); and (vi) sleep disturbance (26).

\section{Summary of findings}

Table 2 shows the findings from each of the three interventions (four papers).

\section{Primary outcomes}

Return-to-work. The number of days until RTW and the median days to sustained RTW ( $\geq 4$ weeks) were lower in the guideline intervention group of workers with low-back pain (51 versus 62 days, compared to usual care) (19) and in the P/T sick leave intervention group (12 versus 20 days, compared to F/T sick leave) (27), respectively. Moreover, patients with musculoskeletal pain in both interventions $(19,27)$ returned to work earlier than those who received usual care [hazard ratio (HR) $1.3,95 \%$ CI 0.9-1.9) and those on F/T sick leave (HR 1.8, 95\% CI 1.2-2.8). In contrast, police workers with mental health problems allocated to the guidelinebased care group did not return to work earlier, compared to the control group (partial RTW: HR 1.0, 95\% CI 0.8-1.3; full RTW: HR 1.0, 95\% CI 0.7-1.3) (25).

Duration (days lost) and rate of recurrence of sick leave. Among workers with low-back pain, the duration of SA after one year did not differ between the guideline-based care (intervention) and the usual-care (control) group (19). In contrast, for the same 1-year follow-up period, Viikari-Juntura et al found that the mean duration of sick leave in the intervention group was $20 \%$ lower compared to the control group (27). Regarding rates of SA recurrence, Viikari-Juntura et al found that the number of recurrent sick leaves per person-year after the initial SA period was $20 \%$ lower in the intervention (P/T sick leave) group (27), while Verbeek et al reported a higher risk of recurrence (HR 2.4, 95\% CI 1.2-4.7) among workers with low-back pain who were allocated to the guideline-based care group (19).

Total productivity loss. No significant differences were reported between the intervention and referral groups in both the duration of sick leave days until full RTW combined with number of days of recurrences on sick leave in the 1-year follow-up (25) and the self-assessed score based on the quality and the amount of work that the participant was able to perform compared to a normal workday (26).

\section{Secondary outcomes}

Satisfaction. Occupational physicians from the guideline-based care group reported higher scores of satisfaction compared to those who evaluated police workers from the control group (25). In the same study, no significant differences were found in employee and employer satisfaction scores (25).

Pain intensity, pain interference with work and sleep, and disability. These characteristics were only assessed in two of the three interventions $(19,26)$, and no significant 
differences were found between the intervention and control groups. $(19,26)$.

\section{Self-reported health and perceived quality of life. Workers} allocated to $\mathrm{P} / \mathrm{T}$ sick leave group reported better selfrated health $(\mathrm{P}=0.06)$ and higher perceived quality of life $(\mathrm{P}=0.01)$ than those allocated to $\mathrm{F} / \mathrm{T}$ sick leave (26).

Health care utilization (19), depressive symptoms (26) and sleep disturbance (26) did not differ between the intervention and control groups.

\section{Bias assessment}

Overall, the three studies have shown a low risk of bias in all the assessed domains of random sequence generation, allocation concealment, incomplete outcome data, and selective reporting. However, when other possible sources of bias were assessed, there are some potential issues that need to be considered. The guideline from Rebergen et al (25) was based on evidence from a study showing an effect only for adjustment disorders. Therefore, it may not have sufficient external validity to be applied to a broad range of mental health symptoms. Moreover, it is possible that the inclusion criteria used in this study might have been too broad leading to a heterogeneous sample, where workers with severe and mild symptoms are grouped together. Furthermore, it is possible that in spite of randomization, there might be some treatment contamination between the intervention and the control because all participating occupational physicians received the same training course. Similarly, in Verbeek et al (19), occupational physician compliance with the guideline could have been better, in particular, on aspects related to the encouragement to remain active, inadequate treatment and follow-up evaluations. Finally, in the Viikari-Juntura et al intervention $(26,27)$, almost all participants were female and came from a limited spectrum of industries; thus, possibly restricting somewhat the external validity of the study.

\section{Meta-analysis}

Pooled risk estimates of RTW and heterogeneity values are shown in figures 2 and 3 . No significant differences were found between the intervention and control groups when the three interventions are included in the metaanalysis (HR 1.3, 95\% CI 0.9-1.9). Furthermore, the heterogeneity reported in this analysis was quite high (figure

1 Very early (<15 days) SA intervention vs. Usual care

1.1 Return-to-work

\begin{tabular}{|c|c|c|c|c|c|c|}
\hline Study or Subgroup & $\log [$ Hazard Ratio] & SE & Weight & $\begin{array}{l}\text { Hazard Ratio } \\
\text { IV, Random, } 95 \% \mathrm{Cl}\end{array}$ & $\begin{array}{c}\text { Hazard Ratio } \\
\text { IV, Random, } 95 \% \mathrm{Cl}\end{array}$ & $\begin{array}{l}\text { Risk of } \\
\text { A B C D }\end{array}$ \\
\hline Rebergen et al. 2009 & -0.0305 & 0.1664 & $36.4 \%$ & $0.97[0.70,1.34]$ & & \\
\hline Verbeek et al. 2002 & 0.2624 & 0.1876 & $33.7 \%$ & $1.30[0.90,1.88]$ & & \\
\hline Viikari-Juntura et al. 2012 & 0.6098 & 0.2181 & $29.9 \%$ & $1.84[1.20,2.82]$ & & \\
\hline Total $(95 \% \mathrm{Cl})$ & & & $100.0 \%$ & $1.30[0.91,1.85]$ & & \\
\hline \multicolumn{5}{|c|}{$\begin{array}{l}\text { Heterogeneity: } \mathrm{Tau}^{2}=0.06 ; \mathrm{Chi}^{2}=5.51, \mathrm{df}=2(\mathrm{P}=0.06) ; \mathrm{I}^{2}=64 \% \\
\text { Test for overall effect: } Z=1.43(P=0.15)\end{array}$} & $\begin{array}{ccccc}0.5 & 0.7 & 1 & 1.5 & 2 \\
\text { Favours [control] } & \text { Favours }\end{array}$ & \\
\hline
\end{tabular}

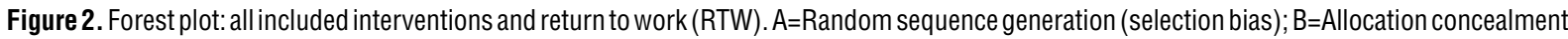
(selection bias); $C=B$ linding of participants and personnel (performance bias); $\mathrm{D}=\mathrm{Blinding}$ of outcome assessment (detection bias); $\mathrm{E}=\mathrm{Incomplete}$ outcome data (attrition bias); $F=S$ Selective reporting (reporting bias); and $\mathrm{G}=0$ ther bias.

1 Very early (<15 days) Guideline SA intervention vs. Usual care

1.1 Return-to-work

\begin{tabular}{|c|c|c|c|c|c|c|}
\hline Study or Subgroup & log[Hazard Ratio] & SE & Weight & $\begin{array}{l}\text { Hazard Ratio } \\
\text { IV, Random, } 95 \% \mathrm{CI}\end{array}$ & $\begin{array}{c}\text { Hazard Ratio } \\
\text { IV, Random, } 95 \% \mathrm{CI}\end{array}$ & $\begin{array}{l}\text { Risk of } \\
\text { A B C D } \\
\end{array}$ \\
\hline Rebergen et al. 2009 & -0.0305 & 0.1664 & $54.4 \%$ & $0.97[0.70,1.34]$ & & \\
\hline Verbeek et al. 2002 & 0.2624 & 0.1876 & $45.6 \%$ & $1.30[0.90,1.88]$ & & \\
\hline Total $(95 \% \mathrm{Cl})$ & & & $100.0 \%$ & $1.11[0.83,1.48]$ & & \\
\hline \multicolumn{5}{|c|}{$\begin{array}{l}\text { Heterogeneity: } \text { Tau }^{2}=0.01 ; \mathrm{Chi}^{2}=1.36, \mathrm{df}=1(\mathrm{P}=0.24) ; \mathrm{I}^{2}=27 \% \\
\text { Test for overall effect: } Z=0.71(P=0.48)\end{array}$} & $\begin{array}{ccccc}0.5 & 0.7 & 1 & 1.5 & 2 \\
\text { urs } & \text { [control] } & \text { Favours [ }\end{array}$ & \\
\hline
\end{tabular}

Figure 3. Forest plot guideline-based care interventions and return to work. $A=$ Random sequence generation (selection bias); $B=A l l o c a t i o n$ concealment (selection bias); $\mathrm{C}=$ Blinding of participants and personnel (performance bias); $\mathrm{D}=\mathrm{Blinding}$ of outcome assessment (detection bias); $\mathrm{E}=$ Incomplete outcome data (attrition bias); $\mathrm{F}=$ Selective reporting (reporting bias); and $\mathrm{G}=0$ ther bias. 
2). Therefore, we decided to perform a sensitivity analysis where only those interventions that are more similar to each other (the two guideline-based care interventions) were included. Again, no significant differences were found between the intervention and control groups (HR $1.1,95 \%$ CI 0.8-1.5). Nevertheless, as expected, heterogeneity decreased considerably (figure 3 ).

\section{Discussion}

This systematic review found limited available evidence regarding the benefits of very early interventions at the workplace in terms of RTW after an episode of SA compared to usual care. It identified no significant differences in relation to productivity loss between workers who received the intervention compared to usual care. Although only three randomized controlled trials classified as high or intermediate quality were identified, it seems that the positive RTW impact in intervening during the first two weeks of SA is somewhat stronger for workers with musculoskeletal disorders and less for workers with mental health problems. Furthermore, early part-time sick leave together with appropriate job modifications have shown to reduce the duration and recurrence of sick leave periods and also to increase self-perception of health and quality of life compared to workers allocated to $\mathrm{F} / \mathrm{T}$ sick leave in a largely female population.

\section{Our findings in the context of previous studies}

Our findings of varying evidence in the included studies of the effectiveness of very early workplace SA interventions in facilitating RTW are in agreement with the current evidence from the Cochrane systematic review of van Vilsteren et al (35). Similarly to this Cochrane review, which included workplace interventions irrespective of timing of commencement, we found some evidence that very early workplace SA interventions also reduce the duration of MSD-related SA episodes but not those related to mental health disorders. In contrast, our results on the impact on SA recurrence rates differ from van Vilsteren et al (35), who report that there is moderate-quality evidence that workplace interventions increase SA recurrences.

In their review on the management of SA, Higgins et al 2012 (36) demonstrated that workplace-based RTW interventions can reduce SA duration; they found moderate evidence that SA is reduced by interventions that include early workplace contact with the worker. Similarly, Carroll et al 2010 (6) report that early intervention is effective in reducing SA. While these results are different from our overall finding of very early inter- ventions not having a significant impact, this may be attributed to the lack of a definition of what constitutes "very early" or "early" interventions. Additionally, the make-up of the included studies may play an influencing role. While all three studies looked at the effectiveness of very early SA intervention (ie, starting $<15$ days after the commencement of SA) they were not looking at very early versus "later" interventions but rather at different interventions.

Moreover, our findings may indicate a possible condition-specific result. We demonstrated that intervening during the first two weeks of SA appears to have a greater impact on workers with MSD disorders and less of an impact on workers with mental health problems. This is similar to the findings of Brown et al (20), who demonstrated a significant reduction in SA due to MSD, gastrointestinal and respiratory disorders versus a non-significant decrease for mental health for healthcare workers undergoing a CBT-based SA workplace intervention starting on day one. Furthermore, Shiri et al, demonstrated that for certain MSD disorders, very early intervention - even before SA starts - can impact the duration of SA immediately following the intervention, but this effect was not sustained in the longer term follow-up (37). This impact of pre-SA intervention on MSD disorders was mirrored in the Viikari-Juntura et al included study, where time to sustained RTW was reduced but also SA duration in the 1-year follow-up was significantly shorter for the intervention group (27).

\section{Interpretation and applicability of these findings}

In all three studies, the control groups received usual care. This is important in the interpretation of our findings, potential explanation of our results and any conclusions drawn. Usual care varies between countries and workplaces depending on a number of factors including $\mathrm{OH}$ provision, social security benefits and SA policy. In some countries, for example this might be very good whilst in others there may be little or no support or provision.

Each of the studies described what usual care comprised. In Rebergen et al, it included advice/input from GP and occupational physicians as well as access to a psychologist (25). In Verbeek et al, it normally entailed seeing a GP, physiotherapist, other medical specialists, and having ordinary supervisor management, including staying in contact with the employee (19). Patients in the usual care group did not see an occupational physician until they were absent for 3 months, unless they requested/insisted and a high number of patients from the usual care group (24\%) crossed over to the intervention group (ie, requested/insisted to be seen by an occupational physician) over the three months (19). Because the authors used intention-to-treat analysis, these patients were analyzed as belonging to the usual care group and 
hence could feasibly have improved the usual care outcomes. In Viikari-Juntura et al, controls were seen by an occupational physician initially (27), both the intervention and control groups received appropriate medical advice, and the need for medical treatments and further possible visits to the physician were determined and made available for individuals in the controls group unable to return to work after their initial period of full time sick leave.

The degree and the timing of input of usual care in the control groups in all three studies could be an explanation for the lack of effectiveness of these "very early" interventions. These matters highlight the feasibility of conducting "natural" experiments in the workplace and the challenges and barriers that exists when attempting to adapt research to fit the real environment and real circumstances.

Another factor that might also contribute to the observed heterogeneous results is the differences in design of the assessed interventions. In the early $\mathrm{P} / \mathrm{T}$ intervention $(26,27)$ work exposures were reduced by restricting work time and modifying tasks when necessary as part of the implementation of the intervention. In contrast, in the two guideline-based care interventions, a group of measures around the diagnoses and management of musculoskeletal (19) and mental health (25) problems were considered as part of the intervention, but it remains unclear what was finally implemented and if it reduced the exposures at work.

\section{Strengths and limitations}

To our knowledge this is the first systematic review to investigate the effectiveness of very early workplace interventions $(<15$ days of SA) to enhance RTW and reduce SA. The implications of this are far reaching for employees, employers, health professionals, governments and society as a whole. It is also pertinent, given that current evidence-based guidelines (1) and recent research $(6,20,21,36,38)$ are providing supporting evidence and advocating early interventions as beneficial in sustaining workability and rehabilitation.

The quality $(29,30)$ and bias (32) assessment of the included studies was based on validated scales, and the included studies cover the most important SA reasons reported in the literature, mental health and MSD. The most recent Health and Safety Executive (HSE) statistics for Great Britain, for example, report that stress, depression or anxiety and MSD accounted for the majority of days lost due to work-related ill health, and that the average days lost per case for mental health disorders (23 days) was higher than for MSD disorders (17 days) (2). Although there are only three included studies, the occupations/sectors covered mirror the sectors where high rates of SA are currently being demonstrated, notably the health and defence sectors (2).
Identification of just three studies of high or intermediate methodological quality, demonstrates the paucity of evidence on very early workplace interventions. This lack of high-quality studies does, however, pose some limitations in the interpretation of our findings in terms of effectiveness and conclusions that can be drawn. There is the lack of a wide range of jobs/sectors covered in the studies, and this can be particularly important as it is recognized that SA differs by sector $(2,39)$. A HSE publication in the UK identified public administration, defence, human health, and social work activities as industry sectors with statistically significantly higher ill health rates compared to all industries (2), and therefore it is of interest to specifically look at all these sectors. The provision of usual care and its potential influence on our results has already been detailed above.

Likewise, external validity of RTW intervention effectiveness depends not only on the comparability of baseline characteristics in source populations but also on full patterns of RTW curves. We have summarised the existing evidence about the effectiveness of very early RTW interventions using single measures of effectiveness that were reported in each study. All included studies were traditionally designed; therefore differences of RTW rates between the intervention and reference groups were estimated assuming that the effect estimates were constant during the time the intervention was implemented, which may not be accurate (17). This fact makes it difficult to compare interventions and therefore, might contribute to the observed lack of effectiveness.

\section{Further recommended research}

Moving forward, a key step would be to reach consensus amongst researchers, stakeholders and policy-makers on the definition of what constitutes an early intervention and the relevant parameters within that context, ie, how early is early, for which sector and under what condition? Inherent to this is understanding the factors influencing when ("time-activating intervention") and how best to intervene, and, specifically, for any given health condition. RTW curves by health condition have been presented in the literature (20), which can assist in informing when to intervene for maximum gain. A number of studies have highlighted the importance of considering not only health and functioning, but also workplace conditions and relations at the workplace in implementing RTW interventions $(6,36,40,41)$. Ekberg et al identified that early RTW among sick-listed individuals with common mental health disorders was associated with the individual's need to secure her/his employment situation, whereas later RTW was associated with variables reflecting dissatisfaction with work conditions (41). Another consideration that this review has highlighted is how this can be assessed in real working conditions. 


\section{Concluding remarks}

Our review has identified a lack of evidence at this point to support "very early" intervention compared to usual care. The methodological design of the studies, notably the extent and timing of usual care provided and variable compliance/crossover between groups, together with the unavailability of full patterns of RTW curves in both intervention and reference groups at different time points, could however explain the lack of demonstrated benefit. Consensus is required on the definition of early intervention and further research is recommended to improve understanding of the factors influencing when and how best to intervene for maximum gain. Randomized controlled trials specifically looking at this research question (ie, early versus late interventions) would be most beneficial.

\section{Acknowledgements}

E Demou was supported by the MRC Strategic Award MC_PC_13027. Paul Herbert and Karen Ritchie, Healthcare Improvement Scotland, contributed to the search engines and databases and J Brown assisted in the development of the search terms.

The authors declare no conflict of interest.

\section{References}

1. Gabbay M, Taylor L, Sheppard L, Hillage J, Bambra C, Ford F, et al. NICE guidance on long-term sickness and incapacity. Brit J Gen Pract. 2011;61:206-7. http://dx.doi.org/10.3399/ bjgp11X561221

2. Health and Safety Executive (HSE). Health and Safety Statistics, Annual report for Great Britain, 2014/2015 [Internet]. [cited 2016 Feb 9] Available from: http://www.hse. gov.uk/statistics/overall/hssh1415.pdf.

3. Gimeno D, Bültmann U, Benavides FG, Alexanderson K, Abma FI, Ubalde-López M, et al. Cross-national comparisons of sickness absence systems and statistics: towards common indicators. Eur J Public Health. 2014;24:663-6. http://dx.doi. org/10.1093/eurpub/cku070

4. Coggon D, Ntani G, Vargas-Prada S, Miguel Martinez J, Serra $\mathrm{C}$, Benavides FG, et al. International variation in absence from work attributed to musculoskeletal illness: findings from the CUPID study. Occup Environ Med. 2013;70:575-84. http:// dx.doi.org/10.1136/oemed-2012-101316

5. Okunribido O, Wynn T, Lewis D. Is age/ageing a risk factor for work-related musculoskeletal disorders? A literature review. In: Anderson M, editor. Contemporary Ergonomics and Human Factors 2010. 1st ed. London: Taylor \& Francis; 2010. p27-35.

6. Carroll C, Rick J, Pilgrim H, Cameron J, Hillage J. Workplace involvement improves return to work rates among employees with back pain on long-term sick leave: a systematic review of the effectiveness and cost-effectiveness of interventions. Disabil Rehabil. 2010;32:607-21. http://dx.doi. org/10.3109/09638280903186301

7. Elders LA, van der Beek AJ, Burdorf A. Return to work after sickness absence due to back disorders--a systematic review on intervention strategies. Int Arch Occup Environ Health. 2000;73:339-48. http://dx.doi.org/10.1007/s004200000127

8. Franche RL, Cullen K, Clarke J, Irvin E, Sinclair S, Frank $\mathrm{J}$, et al. Workplace-based return-to-work interventions: A systematic review of the quantitative literature. J Occup Rehabil. 2005;15:607-31. http://dx.doi.org/10.1007/s10926005-8038-8

9. Palmer KT, Harris EC, Linaker C, Barker M, Lawrence $\mathrm{W}$, Cooper C, et al. Effectiveness of community- and workplace-based interventions to manage musculoskeletalrelated sickness absence and job loss: A systematic review. Rheumatology (Oxford). 2012;51:230-42. http://dx.doi. org/10.1093/rheumatology/ker086

10. van Oostrom SH, Driessen MT, de Vet HC, Franche RL, Schonstein E, Loisel P, et al. Workplace interventions for preventing work disability. Cochrane Database Syst Rev. 2009;(2):Cd006955. http://dx.doi.org/10.1002/14651858. cd006955.pub2

11. Kant I, Jansen NWH, van Amelsvoort LGPM, van Leusden $\mathrm{R}$, Berkouwer A. Structured early consultation with the occupational physician reduces sickness absence among office workers at high risk for long-term sickness absence: A randomized controlled trial. J Occup Rehabil. 2008;18:79-86. http://dx.doi.org/10.1007/s10926-007-9114-z

12. Taimela S, Malmivaara A, Justen S, Laara E, Sintonen H, Tiekso J, et al. The effectiveness of two occupational health intervention programmes in reducing sickness absence among employees at risk. Two randomized controlled trials. Occup Environ Med. 2008;65:236-41. http://dx.doi.org/10.1136/ oem.2007.032706

13. Anema JR, Steenstra IA, Bongers PM, de Vet HCW, Knol DL, Loisel P, et al. Multidisciplinary rehabilitation for subacute low back pain: Graded activity or workplace intervention or both? A randomized controlled trial. Spine (Phila Pa 1976). 2007;32:291-8. http://dx.doi.org/10.1097/01. brs.0000253604.90039.ad

14. Smedley J, Harris EC, Cox V, Ntani G, Coggon D. Evaluation of a case management service to reduce sickness absence. Occup Med (Lond). 2013;63:89-95. http://dx.doi. org/10.1093/occmed/kqs223

15. Steenstra IA, Anema JR, Van Tulder MW, Bongers PM, de Vet $\mathrm{HCW}$, van Mechelen W. Economic evaluation of a multi-stage return to work program for workers on sick-leave due to low back pain. J Occup Rehabil. 2006;16:557-78. http://dx.doi. org/10.1007/s10926-006-9053-0

16. von Thiele Schwarz U, Hasson H. Employee self-rated productivity and objective organizational production levels: effects of worksite health interventions involving reduced work hours and physical exercise. J Occup Environ Med. 2011;53:838-44. http://dx.doi.org/10.1097/ JOM.0b013e31822589c2 
17. van Duijn M, Eijkemans MJ, Koes BW, Koopmanschap MA, Burton KA, Burdorf A. The effects of timing on the costeffectiveness of interventions for workers on sick leave due to low back pain. Occupational and Environmental Medicine 2010, 67:744-50. http://dx.doi.org/10.1136/oem.2009.049874

18. Greenwood JG, Wolf HJ, Pearson JC, Woon CL, Posey P, Main CF. Early Intervention in low-back disability among coal-miners in West Virginia- Negative findings. J Occup Med. 1990;32:1047-52.

19. Verbeek JH, van der Weide WE, van Dijk FJ. Early occupational health management of patients with back pain - A randomized controlled trial. Spine (Phila Pa 1976). 2002;27:1844-51. http:// dx.doi.org/10.1097/00007632-200209010-00006

20. Brown J, Mackay D, Demou E, Craig J FJ, E. M. The EASY (Early Access to Support for You) sickness absence service: A four year evaluation of the impact on absenteeism. Scand J Work Environ Health. 2015;41:204-15. http://dx.doi. org/10.5271/sjweh.3480

21. Demou E, Brown J, Sanati K, Kennedy M, Murray K, Macdonald E. A Novel Approach to Early Sickness Absence Management: The EASY (Early Access to Support for You) Way. Work. 2016;53(3): 597-608. http://dx.doi.org/10.3233/ WOR-152137

22. Hoefsmit N, Houkes I, Nijhuis FJN. Intervention Characteristics that Facilitate Return to Work After Sickness Absence: A Systematic Literature Review. J Occup Rehabil. 2012;22:46277. http://dx.doi.org/10.1007/s10926-012-9359-z

23. FirstCare: Absence Management Solutions [Internet]. [cited 2016 Feb 9] Available from: http://www.firstcare.eu/.

24. Sabbath EL, Melchior M, Goldberg M, Zins M, Berkman LF. Work and family demands: predictors of all-cause sickness absence in the GAZEL cohort. Eur J Public Health. 2012;22:101-6. http://dx.doi.org/10.1093/eurpub/ckr041

25. Rebergen DS, Bruinvels DJ, Bezemer PD, van der Beek AJ, van Mechelen W. Guideline-based care of common mental disorders by occupational physicians (CO-OP study): a randomized controlled trial. J Occup Environ Med. 2009;51:305-12. http:// dx.doi.org/10.1097/JOM.0b013e3181990d32

26. Shiri R, Kausto J, Martimo KP, Kaila-Kangas L, Takala EP, Viikari-Juntura E. Health-related effects of early part-time sick leave due to musculoskeletal disorders: a randomized controlled trial. Scand J Work Environ Health. 2013;39:37-45. http://dx.doi.org/10.5271/sjweh.3301

27. Viikari-Juntura E, Kausto J, Shiri R, Kaila-Kangas L, Takala EP, Karppinen J, et al. Return to work after early part-time sick leave due to musculoskeletal disorders: a randomized controlled trial. Scand J Work Environ Health. 2012;38:13443. http://dx.doi.org/10.5271/sjweh.3258

28. Wendt JK, Tsai SP, Bhojani FA, Cameron DL. The Shell Disability Management Program: a five-year evaluation of the impact on absenteeism and return-on-investment. J Occup Environ Med. 2010;52:544-50. http://dx.doi.org/10.1097/ JOM.0b013e3181dbc8c2

29. Moher D, Schulz KF, Altman D, CONSORT Group (Consolidated Standards of Reporting Trials). The CONSORT statement: revised recommendations for improving the quality of reports of parallel-group randomized trials. JAMA. 2001;285:1987-91. http://dx.doi.org/10.1001/jama.285.15.1987

30. Des Jarlais DC, Lyles C, Crepaz N. Improving the reporting quality of nonrandomized evaluations of behavioral and public health interventions: the TREND statement. Am J Public Health. 2004;94:361-6. http://dx.doi.org/10.2105/ AJPH.94.3.361

31. Rodriguez-Jareno MC, Demou E, Vargas-Prada S, Sanati KA, Skerjanc A, Reis PG, et al. European Working Time Directive and doctors' health: a systematic review of the available epidemiological evidence. BMJ Open. 2014;4:e004916. http:// dx.doi.org/10.1136/bmjopen-2014-004916

32. Higgins JP, Altman DG, Gotzsche PC, Juni P, Moher D, Oxman $\mathrm{AD}$, et al. The Cochrane Collaboration's tool for assessing risk of bias in randomized trials. BMJ. 2011;343:d5928. http:// dx.doi.org/10.1136/bmj.d5928

33. Ruotsalainen JH, Verbeek JH, Marine A, Serra C. Preventing occupational stress in healthcare workers. Cochrane Database Syst Rev. 2015;4:Cd002892. http://dx.doi. org/10.1002/14651858.cd002892.pub5

34. Brouwer WB, Koopmanschap MA, Rutten FF. Productivity losses without absence: measurement validation and empirical evidence. Health Policy. 1999;48:13-27. http://dx.doi. org/10.1016/S0168-8510(99)00028-7

35. van Vilsteren $\mathrm{M}$, van Oostrom $\mathrm{SH}$, de Vet $\mathrm{HC}$, Franche RL, Boot CR, Anema JR. Workplace interventions to prevent work disability in workers on sick leave. Cochrane Database Syst Rev. 2015;10:Cd006955. http://dx.doi. org/10.1002/14651858.cd006955.pub3

36. Higgins A, O'Halloran P, Porter S. Management of Long Term Sickness Absence: A Systematic Realist Review. J Occup Rehabil. 2012;22:322-32. http://dx.doi.org/10.1007/s10926012-9362-4

37. Shiri R, Martimo K-P, Miranda H, Ketola R, Kaila-Kangas L, Liira $\mathrm{H}$, et al. The effect of workplace intervention on pain and sickness absence caused by upper-extremity musculoskeletal disorders. Scand J Work Environ Health. 2011;37:120-8. http://dx.doi.org/10.5271/sjweh.3141

38. Rannard A, Gabbay M, Sen D, Riley R, Britt D. Feasibility trial of GP and case-managed support for workplace sickness absence. Prim Health Care Res Dev. 2014;15:252-61. http:// dx.doi.org/10.1017/S1463423613000133

39. CIPD. Absence Management Survey Report 2015. [Internet]. [cited 2016 Feb 9] Available from: http://www.cipd.co.uk/ binaries/absence-management_2015.pdf.

40. Durand MJ, Corbiere M, Coutu MF, Reinharz D, Albert V. A review of best work-absence management and return-to-work practices for workers with musculoskeletal or common mental disorders. Work. 2014;48:579-89.

41. Ekberg K, Wahlin C, Persson J, Bernfort L, Oberg B. Early and Late Return to Work After Sick Leave: Predictors in a Cohort of Sick-Listed Individuals with Common Mental Disorders. J Occup Rehabil. 2015;25:627-37. http://dx.doi.org/10.1007/ s10926-015-9570-9

Received for publication: 11 February 2016 